\title{
Assessing the Disparities of Per-capita Electricity Consumption in North-Eastern States of India Using Gini Index and Lorenz Curve
}

Sijousa Basumatary ${ }^{1 *}$, Dr. Mridula Devi ${ }^{2}$ and Dr. Konita Basumatary ${ }^{3}$

1,2,3 Department of Economics, Bodoland University, Kokrajhar, Assam, India

Corresponding Author: Author's Name, Sijousa Basumatary E-mail: sbbasu6@gmail.com

\section{ARTICLE INFORMATION}

Received: December 15, 2020

Accepted: January 14, 2021

Volume: 3

Issue: 1

DOI: $10.32996 /$ jhsss.2021.3.1.11

\section{KEYWORDS}

Consumption; Disparities;

Electricity; Per-capita; North-East

\section{ABSTRACT}

Electricity is the basic need for individuals, households and industries. It is used for everyday life activities by the households, agricultural activities, commercial buildings and industries. The per capita electricity consumption is a proxy indicator growth and development status of a region. All the north eastern states consume per-capita electricity lesser than the national average except Sikkim. The per capita consumption of electricity by Nagaland, Assam and Manipur is nearly just one-third of the national average. Notably, these three north eastern states consume just 40 percent of per capita electricity compared to the highest consumer state Meghalaya. The present study is an evaluation of the per-capita electricity consumption trend and inequality amongst the north-eastern states of India using Gini coefficient and Lorenz curve for two different time periods i.e. 2007 and 2017. We find that Tripura's annual linear growth rate of per-capita electricity consumption is the highest ( 3 percent) while that of Meghalaya is the least (1 percent) and the other five states are growing equally at the rate of 2 percent. The Gini coefficient is found to be decreasing from 0.137 in 2007 to 0.122 in 2017. We conclude that the level of inequality is reducing among north eastern states of India though the per-capita consumption of electricity is less than the national average.

\section{Introduction}

Energy is the lifeblood of the global economy and the key input to almost all the goods and services of the modern world (Singh \& Vashishtha, 2020). Electricity has become the basic need for individuals, households and industries. It is used for everyday life activities by the households, by farmers for agricultural activities, commercial buildings and industries to power them. It is the most important input required for our economic growth and human development. Inevitably, access to modern energy is believed to be a prerequisite for sustainable development, poverty alleviation and the achievement of the Millennium Development Goals (Quedraogo, 2013). Against this backdrop, reducing the global disparity in energy is a key to reducing income inequalities, gender inequalities and inequalities in other dimensions such as rural/urban income disparities. (UNDP, 2018). The sustainable development goal 7(SDG7) states that there should be universal access to affordable, reliable and modern energy forms (UNDP, 2015). This SDG 7 is a pre-condition for economic development, poverty alleviation (SDG 1) and reducing inequalities (SDG 10) as the progress on SDG 7 can be seen as a means towards achieving other SDGs and the principle of "Leave no one behind" (UNDP, 2018). Today till the end of 2016 the numbers of people without electricity connection has fallen to just below one billion (UNDP, 2015). As stated by the (UNDP, 2018) unequal access to energy and low human development are highly correlated. Today, India is the third largest consumer as well as the producer of electricity in the world (EIA, 2020) but lowest in terms of per capita electricity consumption (1181 kWh as of 2019). Within India, the north eastern states are found to be consuming the per-capita electricity lesser than the national average except Sikkim. The per capita electricity consumption is fervently the proxy for economic growth and development of a region. Overall, per capita electricity consumption has been considered as one of the most suitable indicator of economic welfare (Kumar, 2014). In this paper we have analysed the differences of per-capita consumption among the north eastern states of India. The paper is organised as follows- The first portion gives introductory view of the need for electricity consumption and its present status in India as well as north-eastern states. The second part describes the methodology and data sources, third section are the results and discussion. The paper ends with overall concluding remarks.

K C AL-KINDI CENTER R D FOR RESEARCH ANC NELOPMENT Your gateway to world-class research

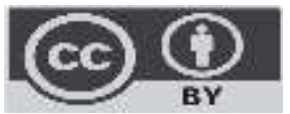

Published by Al-Kindi Center for Research and Development. Copyright (c) the author(s). This open access article is distributed under a Creative Commons Attribution (CC-BY) 4.0 license 


\section{Methodology}

For measuring inequality Gini coefficient and Lorenz curves have been used to ascertain the level of inequality that might exist between the different north-eastern states of India. Gini coefficient measures the inequality among the observed frequency distribution. It measures the extent to which the distribution within an economy deviates from a perfectly equal distribution (DESA, 2015). Here we have taken the per-capita electricity consumption of the individual states for two different time periods i.e. 2007 and 2017 separately as our frequencies. Theoretically; a Gini coefficient of zero implies the existence of perfect equality whereas its value one expresses the existence of perfect inequality. From the data compiled we have also drawn the Lorenz curve to plot the state wise occurrence using MS excel. Secondary data on per-capita electricity consumption of each north-eastern state is compiled from Indiastat.com. Total population of the states for the year 2007 and 2017 is taken as per census data of 2001 and 2011 (Census, 2011). We have used the trend line estimation to check the growth trend of per-capita electricity consumption for each state. The equation is given as

$$
y_{i}=\alpha_{i}+\beta_{i} t
$$

Where $y_{i} \rightarrow \log$ of per-capita electricity consumption of $\mathrm{i}^{\text {th }}$ state

$\alpha_{i} ; \beta_{i} \rightarrow$ Co-efficient of the $\mathrm{i}^{\text {th }}$ state

$t \rightarrow$ Time variable, year i.e. 2007-2017

Figure 1. Map of north-east India

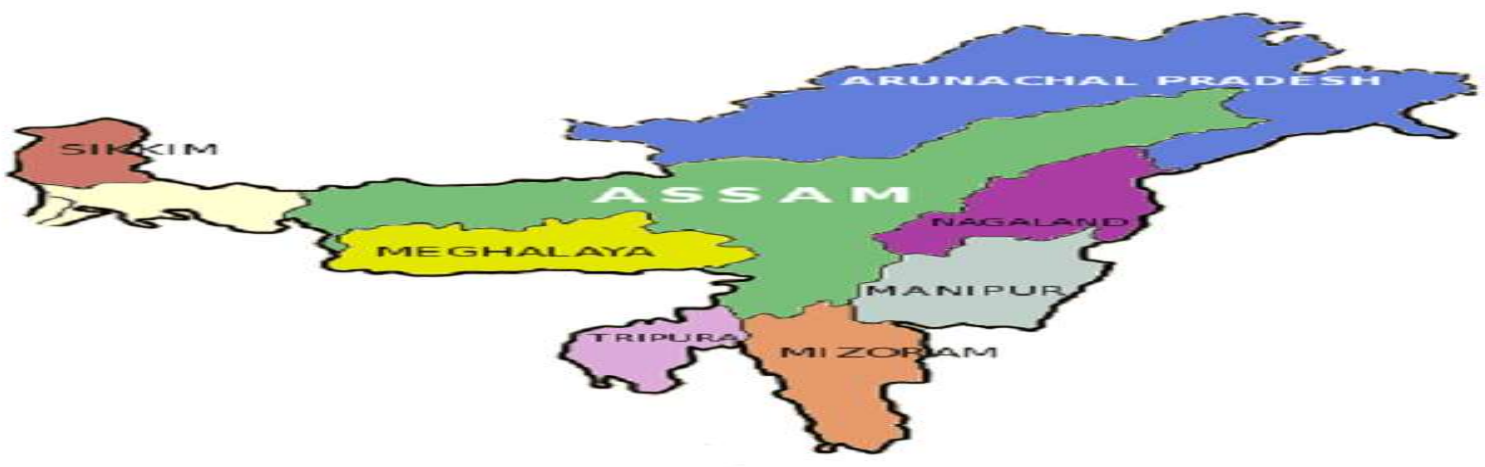

\section{Results and Discussion}

3.1 Trend of per-capita electricity consumption, NE States

Meghalaya is the largest per-capita electricity consumer while Manipur, Tripura, Assam and Nagaland are at the bottom amongst the north-eastern states of India. As of 2017 Meghalaya's per-capita electricity consumption was $832 \mathrm{kWh}$ whereas the average of bottom four states namely Manipur, Tripura, Assam and Nagaland was $370 \mathrm{kWh}$, which is less than half of Meghalaya's percapita consumption. Arunachal and Mizoram is the medium consumer two states with an average of $585 \mathrm{kWh}$ 's of per-capita electricity consumption.

Figure 2. Trend of per-capita electricity consumption, NE States, India

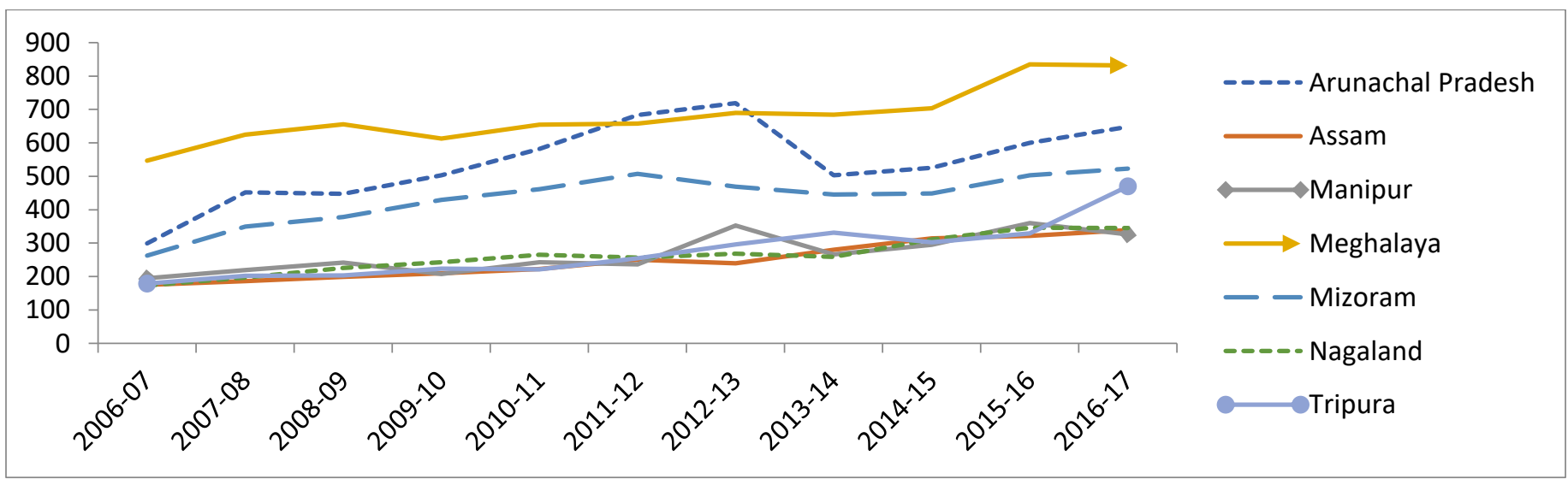


Overall, the per-capita electricity (in $\mathrm{kWh}$ ) consumption of the north-eastern states has been increasing over the years. Inorder to estimate their consumption growth rate we have taken the log of per-capita electricity consumption (in $\mathrm{kWh}$ ) of each state. We find that Tripura's annual linear growth rate of per-capita electricity consumption is the highest (3 percent) while that of Meghalaya is the least (1 percent). The other five states namely, Arunachal, Mizoram, Nagaland, Assam and Manipur are growing equally at the rate of 2 percent. Meghalaya's per-capita electricity consumption is already the highest ( $832 \mathrm{kWh})$ amongst all the north-eastern states so its consumption growth rate is quite slowing down. Notably, all the households in north eastern states of India have been officially declared to be electrified.

Table 1. Trend line of per-capita electricity consumption

\begin{tabular}{lll}
\hline State & Coefficients $\left(\boldsymbol{\beta}^{\prime} \mathbf{s}\right)$ & $\mathrm{R}^{2}$ \\
\hline Meghalaya & 0.01 & 0.832 \\
Arunachal Pradesh & 0.02 & 0.483 \\
Mizoram & 0.02 & 0.675 \\
Tripura & 0.03 & 0.913 \\
Manipur & 0.02 & 0.735 \\
Nagaland & 0.02 & 0.913 \\
Assam & 0.02 & 0.979 \\
\hline
\end{tabular}

Source: Authors calculation

\subsection{Inequality of electricity consumption, NE States, India}

Despite the overall electrification of the households in north-eastern states of India we have found that there are differences in the per-capita electricity consumption amongst them. Therefore, inorder to analyse the inequalities that exists among these north-eastern states, we have used the methodology given in Appendix I for Gini coefficient calculation. We found the Gini index as 0.137 for 2007 and 0.122 for the year 2017. That is the level of inequality of per-capita electricity consumption is gradually decreasing in north-eastern states of India. This implies that the per-capita electricity consumption in the north-eastern states is going to be more and more equal. However, the per-capita electricity consumption equality is still uneven in the north-eastern India. State-wise, Meghalaya is always at the top of the curve, whose per capita consumption has always been the highest while there is a change in the position of bottom consumer state. In 2007 Nagaland was at the bottom but it joined the cluster of other medium per-capita electricity consumer states (Assam, Arunachal Pradesh, Tripura and Mizoram) in 2017 which was replaced by Manipur. As India has been have been making enormous efforts to electrify the un-electrified villages and towns along with the installation of additional electricity generating capacities the north-eastern states is reaping its benefits too.

Figure 3. Lorenz curve, 2007

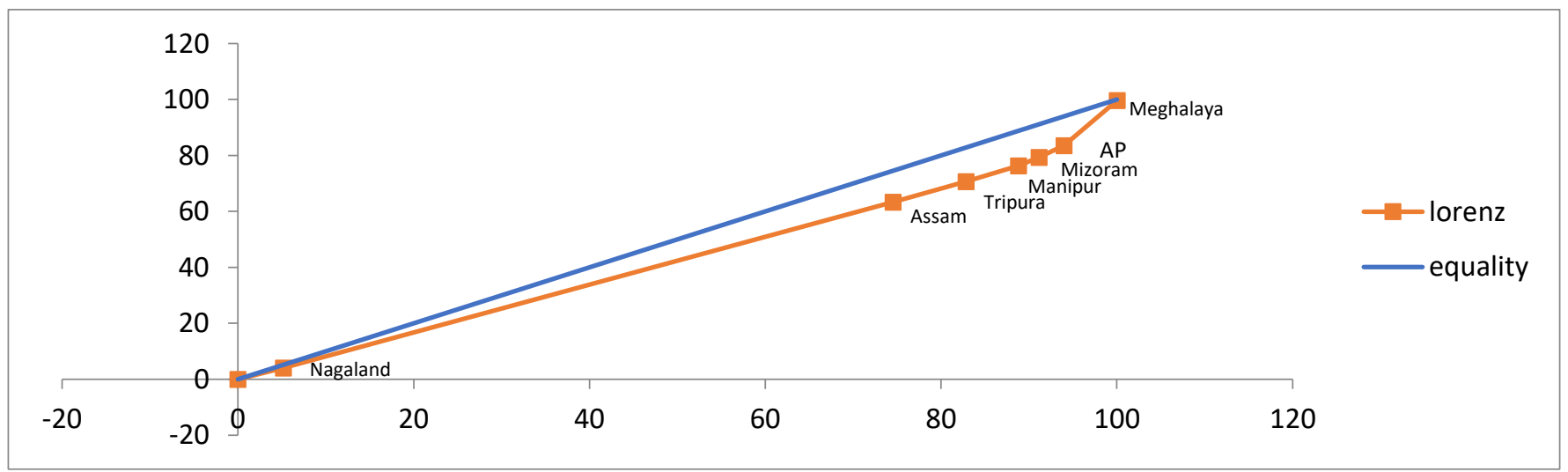


Figure 4 Lorenz curve, 2017

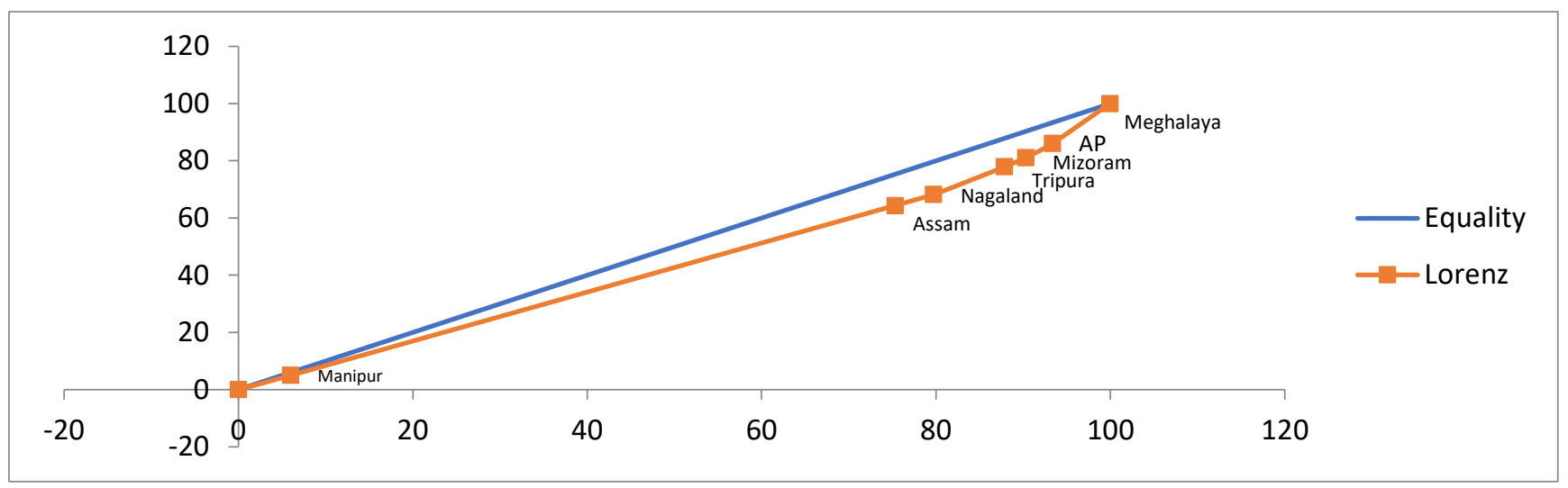

\section{Conclusion}

The north-eastern states of India despite being the consumers of per-capita electricity less than the national average, the percapita electricity consumption has been consistently increasing over the years but with significant differences too based on their size of population and geographical location. As majority of the north-eastern states fall into the hilly regions with harsh terrains for connectivity except Assam it still remains a difficult task for providing $24 \times 7$ electricity services for its households, thereby reducing the per-capita electricity consumption for north-eastern states which is over 19 hours per day as reported by (PIB, 2019). Individual states Tripura and Manipur gets the maximum hours of electricity supply (23.50 hrs per day) and Mizoram gets the least (15 hrs per day), whereas rest of the states continue to manage it with the average hours of supply. This finding is quite interesting for a state like Manipur which lies at the bottom in terms of per-capita electricity consumption (with reference to year 2017) but still manages to provide almost 24 hours of electricity supply. The potential relation for this could be the effective supply and demand matching of electricity demand and supply along with the efficiency measures adopted by the households of Manipur as overall only one-fifth of the rural households (Agrawal, Mani, Aggarwal, Kumar, Jain, \& Ganesan, 2020) in India are aware of BEE (Bureau of Energy Efficiency) standards. Therefore, per-capita electricity consumption inequality in north-eastern states of India could be considerably brought down to a minimum with the combined effort of effective demand-supply management and adoption of BEE standards.

Funding: No funding received

Conflicts of Interest: The authors declare no conflict of interest.

\section{References}

[1] Agrawal, S., Mani, S., Aggarwal, D., Kumar, C. H., Jain, A., \& Ganesan, K. (2020). Awareness and adoption of energy efficiency in Indian homes: Insights from the Indian residential energy survey(IRES) 2020. New Delhi: Council on energy, environment and water.

[2] Census. (2011). Retrieved from https://censusindia.gov.in/2011-prov-results/data_files/india/final_ppt_2011_chapter3.pdf

[3] DESA. (2015, October). Inequality measurement. Development issues No.2 .

[4] EIA. (2020). Country analysis executive summary: India. US Energy information administration.

[5] Guttormsen, A. G. (2007). Causality between energy consumption and economic growth. The journal of energy and development, 33 (1), 122.

[6] Kumar, S. (2014). Convergence in Electricity Consumption in India: A State Level Analysis. Indian Economic Review , 49 (2), $173-191$.

[7] Mahalik, M., \& Mallick, H. (2014). Energy consumption, Economic growth, and financial development: Exploring the empirical linkages for India. The Journal of Developing Areas , 48 (4), 139-159.

[8] PIB. (2019). Electrification of vilages. New Delhi: Govt. of India.

[9] Quedraogo, N. S. (2013). Energy consumption and economic growth: Evidence from the economic community of West African States (ECOWAS). Energy Economics, 36, 637-647.

[10] Rathnayaka, R. M., Seneviratna, D. M., \& Long, W. (2018). The dynamic relationship between energy consumption and economic growth in China. Energy Sources, Part B: Economics, Planning and Policy, 13 (5), 264-268.

[11] Singh, K., \& Vashishtha, S. (2020). Does any relationship between energy consumption and economic growth exist in India? A var model analysis. OPEC Energy Review.

[12] Tariq, G., Sun, H., Haris, M., Javaid, H. M., \& Kong, Y. (2018). Energy Consumption and Economic Growth: Evidence from Four Developing Countries. AMERICAN JOURNAL OF MULTIDISCIPLINARY RESEARCH , 7 (1), 100-107.

[13] UNDP. (2018). Interlinkages among energy, poverty and inequalities. Germany: United Nations.

[14] UNDP. (2015). Sustainable development goals. Retrieved December 2, 2020, from https://www.undp.org/content/undp/en/home/sustainable-development-goals.html 
[15] Agrawal, S., Mani, S., Aggarwal, D., Kumar, C. H., Jain, A., \& Ganesan, K. (2020). Awareness and adoption of energy efficiency in Indian homes: Insights from the Indian residential energy survey(IRES) 2020. New Delhi: Council on energy, environment and water.

[16] Census. (2011). Retrieved from https://censusindia.gov.in/2011-prov-results/data_files/india/final_ppt_2011_chapter3.pdf

[17] DESA. (2015, October). Inequality measurement. Development issues No.2 .

[18] EIA. (2020). Country analysis executive summary: India. US Energy information administration.

[19] Guttormsen, A. G. (2007). Causality between energy consumption and economic growth. The journal of energy and development, 33 (1), 122.

[20] Kumar, S. (2014). Convergence in Electricity Consumption in India: A State Level Analysis. Indian Economic Review , 49 (2), $173-191$.

[21] Mahalik, M., \& Mallick, H. (2014). Energy consumption, Economic growth, and financial development: Exploring the empirical linkages for India. The Journal of Developing Areas, 48 (4), 139-159.

[22] PIB. (2019). Electrification of vilages. New Delhi: Govt. of India.

[23] Quedraogo, N. S. (2013). Energy consumption and economic growth: Evidence from the economic community of West African States (ECOWAS). Energy Economics, 36, 637-647.

[24] Rathnayaka, R. M., Seneviratna, D. M., \& Long, W. (2018). The dynamic relationship between energy consumption and economic growth in China. Energy Sources, Part B: Economics, Planning and Policy, 13 (5), 264-268.

[25] Singh, K., \& Vashishtha, S. (2020). Does any relationship between energy consumption and economic growth exist in India? A var model analysis. OPEC Energy Review .

[26] Tariq, G., Sun, H., Haris, M., Javaid, H. M., \& Kong, Y. (2018). Energy Consumption and Economic Growth: Evidence from Four Developing Countries. AMERICAN JOURNAL OF MULTIDISCIPLINARY RESEARCH , 7 (1), 100-107.

[27] UNDP. (2018). Interlinkages among energy, poverty and inequalities. Germany: United Nations.

[28] UNDP. (2015). Sustainable development goals. Retrieved December 2, 2020, from https://www.undp.org/content/undp/en/home/sustainable-development-goals.html 